\title{
Innovative Modifications for Preventing Mesh Infections Aydinuraz $\mathrm{K}^{*}$ \\ Department of General Surgery, Kirikkale University, Turkey
}

\begin{abstract}
Ventral hernia repair is a field of on-going multidisciplinary scientific research, focusing mainly on creating different prosthetic materials. In daily surgical practice, it is almost impossible to think of an incisional hernia repair without using prosthetic mesh as there has been a significant decrease in hernia recurrence with the incorporation of prosthetic mesh in abdominal wall repairs in the last decades. Mesh infection is a feared complication of prosthetic mesh repairs. It eventually leads to the removal of the mesh and starts the vicious cycle of recurrent incisional hernia repairs. Antibiotic prophylaxis has contradictory results, which raise concern about reaching the minimal inhibitory concentration in the wound before biofilm is produced by bacteria. Modification of mesh texture and changing surface properties by loading the mesh surface with quaternary ammonium compounds, antimicrobial enzymes, antibiotics, triclosan, chitosan, polycations, antimicrobial polymers, silver nanoparticles, nitric oxide have resulted in newly synthesized mesh materials which inhibit biofilm formation and kill bacteria with better surgical outcomes. In the era of multi drug resistant bacteria, nanotechnologic innovations like photodynamic inactivation, fullerenes, carbon nanotubes are promising antibacterial solutions for mesh infections.
\end{abstract}

Keywords: Surgical meshes; Prosthesis-related infections; Hernia repair; Anti-bacterial agents; Metal nanoparticles

\section{Introduction}

The on-going development in different fields of science has greatly helped surgery to evolve continuously. Advances in chemistry, physics, biochemistry and pharmacology have led surgical approaches to become more innovative. Moreover, advances in material science have also made a great impact on successful surgical outcomes.

Currently prostheses are inseparable adjuncts, used in different surgical disciplines for better outcomes, and resulting in increased quality of life and patient satisfaction. Operations for cataract surgery, orthopaedics, breast reconstruction, vascular surgery are carried out using different kinds of prosthetic material.

Incisional hernia repair is also a field of on-going research focusing mainly on application of different prosthetic materials and different surgical techniques. Incisional hernia impairs the quality of life and causes significant morbidity. Nearly $20-25 \%$ of abdominal surgeries end up in incisional hernia [1,2]. Incidence of incisional hernia may even reach $70 \%$ in high risk patients, necessitating risk management as incisional hernia repairs create a huge economic burden [3,4]. Body mass index $>25 \mathrm{~kg} / \mathrm{m}^{2}$, presence of deep space and organ infection, longer operative times, heavily contaminated wounds, bariatric surgery, dependent functional status of the patient, chronic obstructive pulmonary disease, advanced age, higher ASA grades are predictors of early development of incisional hernia after midline laparotomy [3-9]. Moreover, previous ventral hernia repair creates a vicious cycle of recurring ventral hernia repairs and decreases the success rate of surgical repair drastically after each failed repair [10].

In daily surgical practice, it is almost impossible to think of a successful incisional hernia repair without using prosthetic mesh since there has been a significant decrease in hernia recurrence with the incorporation of prosthetic mesh in abdominal wall repairs for ventral hernia [11]. Subsequently, prophylactic mesh augmentation of primary abdominal repair in patients with high risk of incisional hernia was supported by successful results of clinical studies in the early 2000s. Prophylactic mesh augmentation has found a place in abdominal wall closure guidelines that has changed the direction of the debate to choosing the right mesh rather than whether to use mesh or not [12-15].
The necessary properties of prostheses stated by Scales in 1953 are still valid, whether the mesh is synthetic, composite or biologic. The ideal mesh should not be physically modified by tissue fluids and should not excite an inflammatory or foreign body cell response in the tissues. In addition, the mesh should be chemically inert and noncarcinogenic. Furthermore, it should not produce a state of allergy or hypersensitivity and should resist the mechanical strains imposed upon it. It should also be capable of being sterilized and fabricated in a form required with reasonable ease and a relatively low cost. Moreover, it should be resistant to infection [16].

Despite vast scientific literature encouraging mesh repair even in contaminated fields, surgical site infection and the possibility of subsequent mesh removal continues to be a challenge for both the patient and the surgeon. In ventral hernia repairs, the surgeon is always confronted with the dilemma of achieving the best surgical outcome by mesh augmentation while taking a serious risk for mesh infection.

Currently, prophylactic mesh reinforcement even in procedures with a high risk for surgical site infection like ileostomy closure and peritonitis is encouraged [17-21]. Sub-lay light weight macro-porous mesh augmentation is considered a safe approach for it does not increase the incidence of surgical site infection [17]. Prophylactic intraperitoneal placement of composite mesh even in peritonitis is also reported to be safe in a retrospective series [18]. Moreover, prophylactic mesh augmentation in permanent colostomies and ileostomy closure is also found to be safe and cost-effective $[19,20]$.

The incidence of mesh infection is over $15 \%$ in open repairs while it is about $1 \%$ in laparoscopic repairs even though best practice guidelines

*Corresponding author: Aydinuraz K, Department of General Surgery, Kirikkale University Medical Faculty, Turkey, Tel: +90-533-6230882; Fax: +90-3182240786; E-mail: kuzeyaydinuraz@yahoo.com

Received December 25, 2016; Accepted January 28, 2017; Published February 04, 2017

Citation: Aydinuraz K (2017) Innovative Modifications for Preventing Mesh Infections. J Microb Biochem Technol 9: 527-534. doi: 10.4172/1948-5948.1000338

Copyright: () 2017 Aydinuraz K. This is an open-access article distributed under the terms of the Creative Commons Attribution License, which permits unrestricted use, distribution, and reproduction in any medium, provided the original author and source are credited. 
for surgical repair and sterility are followed in abdominal closures. It has been observed that the infected mesh causes pain, erythema, oedema and localized increase in temperature over the mesh implantation area. Presence of fever, malaise and fistula over the mesh area are alarming for an accompanying intra-abdominal abscess that can even lead to sepsis. Consequently, failure of the repair is inevitable once the mesh is infected [22-26].

Mesh infection is determined by properties of bacteria and is facilitated by the host. Host factors leading to increased mesh infection rates are similar to risk factors for incisional hernia. Also, if the hernia repair is augmented using a large microporous mesh or ePTFE, the risk of mesh infection is clearly increased [27-34].

Previous wound infection, colorectal surgery, presence of stoma and damage to gastrointestinal tract during repair are also considered as facilitators of mesh infection although there are studies claiming these conditions are not predictors of mesh infection if a macro-porous lightweight mesh or cost-increasing biologic mesh is used in sub-lay position [28,35-44].

Applying the strict rules of antisepsis and sterility for the surgical intervention can reduce the number of pathogens in the skin and meticulous surgical technique can minimize contamination but it is not always enough to prevent bacterial adhesion and consequent biofilm production, which is the key step in the development of mesh infection [45].

\section{Bacterial adherence}

Bacterial adhesion is the result of the interaction between the bacteria and the mesh. The initial bacterial adherence to the mesh is rapid and reversible. It is mediated by physicochemical factors like electrostatic charges and hydrophobicity. Then, an irreversible adherence ensues via adhesins resulting in secretion of an exopolysaccaride from the bacteria, the biofilm. Biofilms produced by the bacteria have a pivotal role in mesh infection. Once biofilm is formed, complete removal of the implant is nearly mandatory for the eradication of the infection [45-47].

Bacterial load: The bacterial load in the contaminated surgical field in which the mesh is to be implanted is of great concern. Bacterial adherence is substantially increased in highly contaminated surgical fields. In vitro studies show that even bacterial inoculums with very low number of bacteria $(<10$ bacteria) can result in bacterial adherence to the mesh $[48,49]$. Unfortunately, the mesh itself may act as a foreign body, harbouring biofilm producing bacteria. In addition, it potentializes surgical site infection, leading to incisional hernia [25]. When implanted, the mesh reduces the phagocytic activity against the microorganisms. This allows extremely low numbers of bacteria to create infection [26]. Previous wound infection, colorectal surgery, presence of stoma and damage to gastrointestinal tract during repair are still considered as facilitators of mesh infection [28]. Furthermore, clean-contaminated and contaminated wounds are at higher risk for mesh infection [28].

Type of bacteria and colonization: S. epidermidis and S. aureus are residents of the patient's own skin. They are responsible for most of the chronic mesh infections which are usually persistent or recurrent. Streptococcus spp. including group B streptococci, Gramnegative bacteria [including mainly Enterobacteriaceae], anaerobic bacteria [including Peptostreptococcus spp.] and Candida spp. as well as Mycobacterium spp. are also accounted for mesh infections [50-52].

\section{Properties of the mesh}

The same bacterial strains exhibit different adherence patterns to different mesh. Physicochemical properties of the mesh determine the extent of bacterial adhesion and biofilm production. Chemical composition, electrical charge, hydrophobicity, surface roughness and porosity of the biomaterial surface also condition its bio-receptivity [53-56].

Type of polymer: The type of the polymer is one of the main determinants of adhesion. S. epidermidis and S. aureus show an increased affinity to polytetrafluoroethylene polymer in most of the in vitro studies - though little controversy still exists [55-58]. Nevertheless, monofilament unprotected polypropylene and polyester mesh are shown to have least bacterial adherence in vivo [59].

Type of filament and porosity: The type and diameter of the filament are also of upmost importance. Multifilament mesh is more prone to bacterial adhesion when compared with monofilament mesh due to its greater contact surface $[56,59,60]$. Multifilament materials and especially surface roughness, determine microbial adhesion properties. That is, surface irregularities will favour the adhesion and deposition of biofilms while smooth surfaces will be less susceptible to microbial adhesion. Increased filament diameter and increased mesh weight result in increased bacterial adherence for S. epidermidis and $S$. aureus. Lightweight mesh material shows less bacterial adherence whereas S. epidermidis and S. aureus have significantly less adherence to multifilament lightweight composite mesh than multifilament polypropylene mesh [60]. When used in contaminated surgical fields, mesh with larger pores exhibit less bacterial load than mesh with smaller pores unfailingly due to reduced contact surface area and interstices $[32,33,56,61]$.

Fixation of the mesh: Bacterial adherence to the suture materials used to anchor the mesh to the body is another determinant of mesh infection. Anchoring the mesh even with monofilament polypropylene increases the bacterial load of the implant [56]. Nonetheless, to eliminate the burden of extra foreign material in the surgical field, fixation of the mesh solely with fibrin glue has proven to be safe and effective [62-64].

\section{Antibiotic prophylaxis and prolonged antibiotic administration}

Antibiotic prophylaxis has partly been helpful in overcoming mesh infections. The aim of prophylactic antibiotic administration is to minimize bacterial count in the wound and decrease adherence to the mesh and prevent biofilm production; thereby blocking the key step for mesh infection. In clinical studies, prophylactic administration of sulbactam-ampicilline or cefazolin is shown to reduce surgical site infections significantly in open hernia repairs with mesh [65-67]. If the patient has a history of methicillin-resistant $S$. aureus [MRSA] surgical site infection, perioperative intravenous antibiotic administration followed by prolonged postoperative oral antibiotic administration has been observed to minimize impending mesh infection [44]. Prolonged postoperative antibiotic administration has also been proven to reduce surgical site infection in ventral hernia repairs, where presence of surgical drains increases the risk of surgical site infection [68].

When the biofilm forms over the mesh, it protects bacteria from the effects of systemic antibiotics. Reaching an effective inhibitory concentration around the mesh requires administration of a higher dose of antibiotic, which can sometimes be toxic to the patient. Therefore, the antibiotic concentration in the wound has always raised a question about the efficacy of prophylaxis. Yet, in a prospective randomized control study, the results did not support preoperative administration of single dose of cefazolin [69]. 
This phenomenon has led scientists and surgeons to search for local innovative solutions so as to block mesh infection because usually the single effective intervention that can be applied is to remove the mesh in infected cases and to try to repair the defect without using prosthetic material [70-75].

\section{Mesh modifications}

The ideal antibacterial surface should prevent the initial bacterial attachment before biofilm is formed. It should kill the bacteria in the milieu and should remove the dead bacteria to minimize inflammation. Creating an antibacterial surface is a complicated process ranging from pre-soaking to plasma coating and nano-crystalline coating. (Shown as supplementary Table 1).

Pre-soaking: Twenty years ago, the first experimental studies about local application of antibiotics had successful results indicating that local application of antibiotics before mesh implantation was as good as intravenous antibiotic administration. Local application was succeeded by pre-soaking the mesh in antibiotics or disinfectants just before implantation, aiming to kill the bacteria in the milieu. Although results of in vitro studies for pre-soaking are promising, in vivo experiments have proven to be the opposite. Pre-soaking different types of mesh with vancomycin has shown to be effective in vitro only. The studies by Pérez-Köhler et al. showed that, soaking the mesh with gentamycin and different combinations of vancomycin and allicin-chlorhexidine resulted in a higher success in vitro and a lower success in vivo. In a recent prospective randomized study by Yabanoğlu et al., investigating the effect of soaking the mesh in vancomycin before implantation on wound infection rates in ventral hernia repair, there was no difference between pre-soaking the mesh in vancomycin and saline. It has been observed that the release and degradation rates of the antimicrobial, the concentration in the wound are difficult to assess and reproduce with pre-soaking technique [76-81].

Surface coating: Surface coating aims to create bactericidal surfaces, bacteria resistant surfaces and bacteria release surfaces. The mesh surface is coated with antibacterial agents, adhesion inhibitors and metal ions $[82,83]$.The bactericidal coating with antibacterial substances can be contact-based, release-based or may be both contact and releasebased. These antibacterial substances can also have switchable bactericidal activity $[82,83]$. The bactericidal coating should have a controlled degradation rate. It should be non-toxic and absorbable. Moreover, the coating should change neither tissue integration, wound healing nor biochemical properties of the mesh [84].

Antibacterial surfaces: Quaternary ammonium compounds, antimicrobial enzymes, antibiotics, chitosan, polycations, antimicrobial polymers, silver or gold nanoparticles and nitric oxide are used either for contact-based or release-based antibacterial coating [83,85].

Quaternery ammonium compounds: Quaternery ammonium compounds destabilize the bacterial cytoplasmic membrane. The quaternary ammonium silane of 3-(trimethoxysilyl)propyldimethyloctadecyl ammonium chloride is a typical example for creating contact- based bactericidal surface. N,N-dimethyl-N-benzyl$\mathrm{N}$-(2-methacryloyloxyethyl) ammonium bromide has been also used as a carrier for chlorhexidine in a recent study and has been shown to exhibit bactericidal activity against $S$. aureus and S. epidermidis, similar to chlorhexidine [86].

Antimicrobial enzymes: Antimicrobial enzymes which belong to innate immune system are also promising as they are less susceptible to proteolysis and kill bacteria rapidly. Antimicrobial enzymes consist of three different subgroups, namely proteolytic enzymes, polysaccharidedegrading enzymes, and oxidative enzymes [87].

Lysostaphin which is a zinc metalloenzyme with specific lytic action against $S$. aureus is an example for antimicrobial polypeptides. The compound consists of three enzymes one of which is glycylglycine endopeptidase. It cleaves the glycine-glycine bonds in S. aureus cell wall. These bonds are responsible for the crosslinking of peptides in the bacteria wall and provide extreme mechanical strength unique to $S$. aureus cell wall [88]. Several experimental studies have all shown that lysostaphin coating is effective for eradicating S. aureus both in vivo and in vitro. Moreover, lysostaphin coating is effective in a dose dependent manner and can be used effectively for coating polypropylene mesh, human acellular dermis and porcine bio-mesh and it is even effective in contaminated surgical fields [89-92].

Antibiotics: There are numerous studies about surface coating with antibiotics. Antibiotics are either adsorbed to the mesh surface by covalent conjugation or by physical adsorption, if creating a contactbased bactericidal surface is aimed. To create release-based bactericidal surfaces, antibiotics are compounded with non-toxic biocompatible polymers and are coated on the mesh surface.

Such biocompatible polymers chemically modify the surface of mesh and enhance the sorption capacity by changing the hydrophobicity of the surface. This modification leads to sustained release of the antibiotic, targeting concentration levels above the minimal inhibiting concentration [93].

Cefazolin is the most common antibiotic used for antibacterial prophylaxis. In an experimental study, in which the polypropylene mesh was coated with cefazoline dispersed in poly(DL-lactide-coglycolide) solution, the newly synthesized mesh was found to show high antibacterial activity both in vitro and in vivo [94].

In another in vivo experimental study, a completely absorbable, hydrophilic, polyglycolic acid-trimethylene carbonate prosthesis impregnated with two different concentration of cefazoline was implanted intraperitoneally and infected with S. aureus. It was observed that impregnation of the mesh with cefazolin prevents the infection of the prosthesis placed in infected wound [95].

Amoxicilline and quinolons are other antibiotics used commonly for antimicrobial prophylaxis. In an experimental study conducted both in vitro and in vivo, coating solution was made up of polylactic acid dissolved in acetone. Amoxicillin and ofloxacin powder dispersed in a viscous polymer solution was added to the media. Standard polypropylene mesh with macro-porous and knitted monofilament was used. The release rate of both amoxicilline and ofloxacin were found to be high for three days in vitro while neither clinical nor microbial findings of infection could be detected in the in vivo part of the experiment [96].

In an experimental study, the increase in the amount of amoxicilline loaded on polypropylene mesh after plasma functionalization and polymerization was investigated by release studies, antibacterial assays and cell culture. It was shown that plasma functionalization and polymerization increased the amount of amoxicilline loading nearly 3 folds; thereby increasing the amount of antibiotic release in the wound effectively [97].

Coating the mesh surface with cyclodextrin and maltodextrin in order to prolong ciprofloxacine delivery is also shown to be effective against $S$. aureus, S. epidermidis and E. coli in another in 
vitro study, where the mesh surface was functionalized with citric acid and hydroxypropyl- $\gamma$-cyclodextrin or maltodextrin. Integration of ciprofloxacine to the cyclo- or malto-dextrin crosslinked polymer coating increased the sustained release and consequently, increased antimicrobial efficacy of ciprofloxacine by 2.8 in maltodextrin coating and 4.2 fold in cyclodextrin coating [93].

A degradable coating consisting of poly[ $\varepsilon$-caprolactone] was successfully used as a carrier for the sustained release of ofloxacine in an in vitro experiment. Mesh was coated with the polymer using airbrush spraying technology. In a succeeding study by the same group, ofloxacin and rifampicin were both dispersed in a degradable polymer reservoir made up of [poly[ $\varepsilon$-caprolactone] and poly [DL-lactic acid]. While the sustained release of ofloxacine and rifampicin continued for at least for $72 \mathrm{~h}$, microorganism adhesion, biofilm formation and bacterial growth around the mesh were significantly reduced $[98,99]$.

Vancomycin has long been the choice for treatment of methicillin resistant $S$. aureus infections. Coating the mesh with vancomycin has also been successful both in vitro and in vivo. In an in vivo experimental model by Harth et al., polyester mesh was coated with a solution of b-cyclodextrin prepolymer and polyethylene glycol di-glycidyl ether and was submerged in to aqueous vancomycin for four days. Afterwards, the mesh was implanted subcutaneously in dorsum of rats with S. aureus inoculation. The results of the study showed that the drug delivery continued up to 4 weeks without signs of infection [84].

Coating lightweight polypropylene mesh with a non-cross-linked copolymer of 2-hydroxyethyl methacrylate and 2-acrylamido-2methylpropanesulfonic acid and integrating the coating with aqueous vancomycin has shown sustained release against $S$. aureus and $S$. epidermidis for at least 14 days in vitro and 30 days in vivo even with low doses of the antibiotic. The acrylic polymer system was shown to regulate the release of the antibiotic with a rate of $24 \mu \mathrm{g} / \mathrm{h} \mathrm{[100].}$

Junge et al. have shown in an in vitro and in vivo experimental study that implantation of gentamicin loaded polyacrylic monomer coated polyvinylidenfluoride mesh significantly reduced infection rates in an animal model while it showed sustained release of gentamicin in vivo [101]. In an experimental study by Klink et al., an optimized plasmainduced graft polymerization was used to create a polyacrylic acid monomer layer on the surface of the mesh and gentamicin was bound to the active sites of the grafted mesh. The initial gentamicin loading was $5.4 \pm 0.3 \mu \mathrm{g} / \mathrm{ml}$. By the end of a week, $73 \%$ of gentamicin was released in vitro. The in vivo release was highest at $1 \mathrm{~h}$ after implantation with detectable serum levels of gentamicin [102].

\section{Antibiotic resistance and promising solutions}

Resistance to antimicrobial drugs has become a significant threat to human health over the years. The antibiotics are not enough to overcome infections due to emerging multi drug resistant microorganisms. This situation results in longer hospital stays and increased mortality. The resistance developing mechanisms of bacteria are clearly faster than our pace of inventing new antibiotics. Moreover, there is always the risk that bacteria will gain resistance to the newly synthesized antibiotics. Therefore, there is clearly a need for antimicrobials to which multi drug resistant bacterial strains cannot develop any resistance. Applications of nitric oxide, triclosan, chitosan, metallic nanoparticles, photodynamic inactivation, fullerenes and carbon nanotubes are promising against multi drug resistant bacteria [103].

Nitric oxide: Nitric oxide is an important mediator of innate immune response with both cytotoxic and cytostatic effects on pathogenic organisms. These effects are the result of oxidative and nitrosative stress generated by reactive intermediates of nitric oxide, resulting in damage to DNA, proteins and cell membranes. Nitric oxide is metabolized very rapidly by human metabolism in order to prevent toxicity [104,105]. In a study by Engelsman et al., monofilament polypropylene mesh was coated with a low concentration NO-releasing carbon-based coating. The mesh showed significant bactericidal effect against S. aureus, E. coli, $P$. aeruginosa and coagulase-negative staphylococcus in vitro part of the study while such an effect could not be detected for subcutaneously implanted mesh in mice [104].

Triclosan: Triclosan (2,4,4-trichloro, 2-hydroxydiphenylether) is a non-cationic antimicrobial. At low concentrations, triclosan is bacteriostatic and it inhibits fatty acid synthesis in the bacteria. At higher concentrations, it is bactericidal and destabilizes bacterial membranes. Triclosan has broad spectrum activity against gram positive and gram negative bacteria as well as virus and fungi. Triclosan resists hydrolysis and remains stable in acidic environments like the wound itself. The chemical interactions result from secondary bonding through ether, oxygen and phenyl hydroxyl functional groups. Bacterial membrane phospholipids are disrupted by rapid triclosan fluctuating bond rotations. Although triclosan has been used for years its antimicrobial property, there is no data about bacterial resistance in humans [106].

In an in vivo study by Cakmak et al., polypropylene grafts incubated overnight with triclosan loaded high molecular weight chitosan were contaminated with $100 \mu \mathrm{L}$ S. aureus suspension just before their implantation in the inguinal region of the rats. The modified mesh was shown to release triclosan for 7 days. No macroscopic signs of local infection could be detected in rats in which polypropylene mesh incubated with triclosan loaded high molecular weight chitosan was implanted [107].

\section{Nanotechnology}

Chitosan: Chitosan is a biocompatible and bio-absorbable natural linear polycationic polymer. Chitosan containing nanoparticles use multiple mechanisms to kill bacteria; therefore bacterial resistance seems to be unlikely. It is a long polymer chain with random number of $\mathrm{N}$-acetyl-glucosamine residues. These positively charged residues associate with the negatively charged bacterial wall and plasma membranes and creates osmotic damage by increasing the permeability of the microbial cell membrane. Chisotan nanoparticles chelate metals and decreases metalloprotein activity in the cell. It binds to DNA of the bacteria and inhibits transcription of mRNA and protein translation. Low molecular weight chitosan nanoparticles are more effective against gram negative bacteria while high molecular weight chitosan nanoparticles are effective against gram positive bacteria [103]. Cefepime and vancomycine loaded chitosan microspheres were shown to be bactericidal in vitro studies. Thus, nanoconjugation of chitosan microspheres with antibiotics seems to be a promising antibacterial mechanism [108,109].

Metal oxides: Metal oxide nanoparticles are promising antimicrobial agents. These nanoparticles ranging in size from 1 to $100 \mathrm{~nm}$ are available in different size and shapes. The particle volume/ surface area ratio is important for their bactericidal properties. Metal oxide nanoparticles exert their antimicrobial activity via different mechanisms. They create cell membrane damage by electrostatic interaction and disturb the metal/metal ion homeostasis within the bacteria. They produce reactive oxygen species. Catalytic activity of intracellular enzymes is annihilated and bacterial signal transduction 
is inhibited. In addition to these antimicrobial effects, metal oxide nanoparticles also serve as carriers for antibiotics [110,111].

Silver has been used for centuries because of its antimicrobial properties. Toxicity of silver ions to humans and the advent of antimicrobial drugs have limited the use of silver. Yet, in the last two decades, nanotechnology has enabled the widespread use of silver nanoparticles which have antimicrobial effects with lesser toxicity. Silver nanoparticles with $10-100 \mathrm{~nm}$ size were shown to have strong bactericidal effect against both Gram-positive and Gram-negative bacteria. They are also effective against microorganisms like $P$. aeruginosa, ampicillin-resistant $E$. coli, erythromycin-resistant $S$. pyogenes, methicillin- resistant $S$. aureus and vancomycin-resistant $S$. aureus. The antimicrobial activity of silver nanoparticles depends upon their volume and shape. Nanoparticles with small volume and larger surface area easily pass through peptidoglycan cell walls and cell membranes [103,112-114].

Silver nanoparticles are prepared by different physical methods such as spark discharging, electrochemical reduction, cryochemical synthesis and electrochemical reduction. Silver nanoparticles have compiled different antibacterial modes of action. Silver ions interact with sulphur-containing and phosphorus-containing proteins of bacterial cell wall and plasma membrane and create holes in the membrane. The disruption of the cell wall leads cytoplasmic content of the bacteria to leak out. If the bacteria survive this insult, the silver nanoparticles penetrate into the plasma and inhibit cytochromes of electron transport of the bacteria, damage bacterial DNA and RNA, inhibit DNA replication and cell division. Silver nanoparticles also prevent protein translation by denaturing 30S ribosomal subunit and inhibit cell wall synthesis. Silver nanoparticles form reactive oxygen species also. It is highly unlikely for the bacteria to develop resistance against silver nanoparticles with such a compilation of bactericidal activities [103,112-114].

Polypropylene mesh was coated with nano-crystalline silver using physical vapor deposition in a study by Cohen et al. In vitro analysis after incubation with $S$. aureus showed that there was a dose-dependent bactericidal effect of nano-crystalline silver that was also evident in scanning microscopic microscopy [115]. Polyethylene terephthalate mesh coated by plasma polymerized polyacrylic acid and silver nanoparticles was entrapped on the coated mesh by chemical reduction in an experimental study by Kumar et al. This modified mesh proved to have excellent antibacterial effect for both S. aureus and E. coli in in vitro tests [116].

Not only silver but other metal containing nanoparticles such as gold, magnesium, copper, zinc and titanium, also have antibacterial potential for drug resistant microorganisms. In a study by Saygun et al., polypropylene mesh pieces were sputtered with gold-palladium. After incubation with $S$. Epidermidis, they were laid under the musculoaponeurotic layer of inguinal region of rats. Gold-palladium coated polypropylene mesh showed the least bacterial growth in vitro and no signs of infection in vivo [117].

Titanium dioxide containing nanoparticles exert their antimicrobial activity mainly via two mechanisms. When titanium dioxide nanoparticles are exposed to near UV and UVA radiation, they generate reactive oxygen species such as hydrogen peroxide and hydroxyl radicals. The generated reactive oxygen species damage bacterial cell membranes and compromise membrane permeability. At the same time, oxidative phosphorylation is hampered. It is worthy to note that even without UVA radiation, titanium dioxide containing nanoparticles may still have bactericidal effects [103]. Coating the surface with titanium dioxide creates photoactivated antimicrobial surfaces which have self-cleansing and self-disinfection properties. Bacteria and biofilm adhesion are prevented by degradation of organic substances by total oxidation [118].

In an in vitro study by Aboelzahab et al., $1 \times 1 \mathrm{~cm}$ mesh pieces coated with titanium by aqueous plasma electrodisposition were first activated by infrared laser for $30 \mathrm{~s}$ and afterwards they were introduced into bacterial suspension of $S$. aureus with a concentration of $7.93 \times 10^{7}$ cells $/ \mathrm{ml}$. The survival/necrosis rate of microorganisms was determined by post-confocal imaging. The necrosis of $S$. aureus cells was found to exceed $90 \%$ within the first thirty minutes [119].

Photodynamic inactivation: Photodynamic inactivation is a promising approach to kill bacteria and inhibit biofilm formation. The microorganisms treated with a photosensitizer are irradiated afterwards with appropriate wavelength of visible light. The cytotoxic reactive oxygen species generated by this application exerts a bactericidal effect. Photodynamic activation increases the antibacterial efficacy of metallic nanoparticles as in titanium dioxide particles or silver nanoparticles. It also increases the antimicrobial activity of antibiotics. Photodynamic inactivation has been shown to exert bactericidal effect against methicilline resistant $S$. aureus, S. epidermidis, E. coli, P. aeruginosa and A. baumanii. The most common chemical structures are naturally occurring pigments such as heme, chlorophyll and bacteriochlorophyll. Synthetic conjugated pyrrolic ring systems such as texaphyrins, porphycenes and phthalocyanines are the second group of photosensitizers. Nontetrapyrrole-derived dyes, which can be either synthetic or natural, are often used as antimicrobial photosensitizers. Hypericin, toluidine blue $\mathrm{O}$ and Rose Bengal belong to this group [120-126].

Carbon nanoparticles: Graphenes, carbon nanotubes and fullerenes are carbon nanomaterials with antibacterial properties. They are hydrophobic and they have oxidation properties [127]. Carbon nanotubes are cylindrical nanostructures comprised of hexagonal arrays of covalently bonded carbon atoms. They can be described as hollow structures with an extremely high aspect ratio, which are formed by rolled graphene sheets. Carbon nanotubes have two distinct types: single walled nanotubes and double walled nanotubes. Single walled nanotubes possess the strong antimicrobial activity. It is poorly soluble and this can be limiting its use. After its contact with the bacteria, the carbon nanotubes directly puncture the membrane and membrane oxidation follows [127-129].

Fullerenes are closed cage carbon allotropes. The most studied Buckminsterfullerene has 60 carbon atoms. Fullerenes are spherical in shape and have a diameter about $1 \mathrm{~nm}$. They have good absorption of visible light. When illuminated, they have a high yield of reactive oxygen species $[127,130]$. Fullerenes may have a medical application in photodynamic inactivation when they are made more soluble. Fullerenes show both kinds of photochemistry comprising type I (free radicals) and type II (singlet oxygen). They are non-toxic. Fullerene cages can also be used vesicles for improved drug delivery [126,127]. In a study by Mizuno et al., it was shown that cationic-substituted fullerene derivatives were highly bactericidal after illumination with white light. Fullerene derivatives that possessed either basic or quaternary amino groups were synthesized. Quaternary cationic groups were widely dispersed around the fullerene cage. S. aureus was most susceptible to quaternized fullerenes [131]. 


\section{Conclusion}

Ventral hernia repair complicated by infected mesh is a serious problem creating significant morbidity for the patient. In the greater scale, mesh infections account for a considerable economic burden on health economy. In addition to this, there is a severe threat of infections with multidrug resistant bacteria where antibiotics are ineffective. Therefore, local solutions in the wound to reach minimal inhibitory concentrations of antibiotics without creating toxicity and local application of promising molecules with antibacterial activity and nanotechnologic approaches for controlling the infection at the very initial stage of bacteria mesh interaction before the biofilm develops seems to be a rational approach. With the progress in material science and its collaboration with general surgery, the ideal antibacterial mesh will hopefully be created in the near future.

\section{References}

1. Burger JW, Lange JF, Halm JA, Kleinrensink GJ, Jeekel H (2005) Incisional hernia: Early complication of abdominal surgery. World J Surg 29: 1608-1613.

2. van Ramshorst GH, Eker HH, Hop WC, Jeekel J, Lange JF (2012) Impact of incisional hernia on health-related quality of life and body image: A prospective cohort study. Am J Surg 204: 144-150.

3. Veljkovic R, Protic M, Gluhovic A, Potic Z, Milosevic Z, et al. (2010) Prospective clinical trial of factors predicting the early development of incisional hernia after midline laparotomy. J Am Coll Surg 210: 210-219.

4. Gillion JF, Sanders D, Miserez M, Muysoms F (2016) The economic burden of incisional ventral hernia repair: A multicentric cost analysis. Hernia 20: 819-830.

5. Fischer JP, Wink JD, Tuggle CT, Nelson JA, Kovach SJ (2015) Wound risk assessment in ventral hernia repair: Generation and internal validation of a risk stratification system using the ACS-NSQIP. Hernia 19: 103-111.

6. Fischer JP, Basta MN, Mirzabeigi MN, Bauder AR, Fox JP et al. (2015) A risk model and cost analysis of incisional hernia after elective, abdominal surgery based upon 12,373 cases: The case for targeted prophylactic intervention. Surgery 263: 1010-1017.

7. Le Huu Nho R, Mege D, Ouaïssi M, Sielezneff I, Sastre B (2012) Incidence and prevention of ventral incisional hernia. J Visc Surg 149: e3-14.

8. Goodenough CJ, Ko TC, Kao LS, Nguyen MT, Holihan JL et al. (2015) Development and validation of a risk stratification score for ventral incisional hernia after abdominal surgery: Hernia expectation rates in intra-abdominal surgery (the HERNIA Project). J Am Coll Surg 220: 405-413.

9. Caglià P, Tracia A, Borzì L, Amodeo L, Tracia L, et al. (2014) Incisional hernia in the elderly: Risk factors and clinical considerations. Int J Surg 12: S164-169.

10. Holihan JL, Alawadi Z, Martindale RG, Roth JS, Wray CJ, et al. (2015) Adverse events after ventral hernia repair: The vicious cycle of complications. J Am Coll Surg 221: 478-485

11. Burger JW, Luijendijk RW, Hop WC, Halm JA, Verdaasdonk EG, et al. (2004) Long-term follow-up of a randomized controlled trial of suture versus mesh repair of incisional hernia. Ann Surg 240: 578-585.

12. Bhangu A, Fitzgerald JE, Singh P, Battersby N, Marriott P, et al (2013) Systematic review and meta-analysis of prophylactic mesh placement for prevention of incisional hernia following midline laparotomy. Hernia 17: 445-455.

13. Klinge U, Weyhe D (2014) Hernia surgery: Minimization of complications by selection of the correct mesh. Chirurg 85: 105-111.

14. Fischer JP, Basta MN, Wink JD, Krishnan NM, Kovach SJ (2015) Cost-utility analysis of the use of prophylactic mesh augmentation compared with primary fascial suture repair in patients at high risk for incisional hernia. Surgery 158 700-711.

15. Muysoms FE, Antoniou SA, Bury K, Campanelli G, Conze J, et al. (2015) European Hernia Society guidelines on the closure of abdominal wall incisions. Hernia 19: 1-24.

16. Scales JT (1953) Tissue reactions to synthetic materials. Proc R Soc Med 46 647-652.

17. Argudo N, Pereira JA, Sancho JJ, Membrilla E, Pons MJ, et al. (2014) Prophylactic synthetic meshes can be safely used to close emergency laparotomies, even in peritonitis. Surgery 156: 1238-1244.
18. Kurmann A, Barnetta C, Candinas D, Beldi G (2013) Implantation of prophylactic non-absorbable intraperitoneal mesh in patients with peritonitis is safe and feasible. World J Surg 37: 1656-1660

19. Lee L, Saleem A, Landry T, Latimer E, Chaudhury P, et al. (2014) Cos effectiveness of mesh prophylaxis to prevent parastomal hernia in patients undergoing permanent colostomy for rectal cancer. J Am Coll Surg 218: 82-91.

20. Liu DS, Banham E, Yellapu S (2013) Prophylactic mesh reinforcement reduces stomal site incisional hernia after ileostomy closure. World J Surg 37: 2039-2045.

21. Fischer JP, Basta MN, Wink JD, Krishnan NM, Kovach SJ (2015) Cost-utility analysis of the use of prophylactic mesh augmentation compared with primary fascial suture repair in patients at high risk for incisional hernia. Surgery 158: 700-711.

22. Bosanquet DC, Vaughan S, Stephenson BM (2015) Late mesh sepsis: How late is late? Hernia 19: 1035-1036.

23. Wink JD, Wes AM, Fischer JP, Nelson JA, Stranksy C, et al. (2015) Risk factors associated with early failure in complex abdominal wall reconstruction: A 5 year single surgeon experience. J Plast Surg Hand of Surg 49: 77-82.

24. Itatsu K, Yokoyama Y, Sugawara G, Kubota H, Tojima Y, et al. (2014) Incidence of and risk factors for incisional hernia after abdominal surgery. Br J Surg 101: 1439-1447.

25. Narkhede R, Shah NM, Dalal PR, Mangukia C, Dholaria S (2015) Postoperative mesh infection-still a concern in laparoscopic era. Indian J Surg 77: 322-326.

26. Engelsman AF, van Dam GM, van der Mei HC, Busscher HJ, Ploeg RJ (2010) In vivo evaluation of bacterial infection involving morphologically different surgical meshes. Ann Surg 251: 133-137.

27. Mavros MN, Athanasiou S, Alexiou VG, Mitsikostas PK, Peppas G, et al. (2011) Risk factors for mesh-related infections after hernia repair surgery: A metaanalysis of cohort studies. World J Surg 35: 2389-2398.

28. Choi JJ, Palaniappa NC, Dallas KB, Rudich TB, Colon MJ et al. (2012) Use of mesh during ventral hernia repair in clean-contaminated and contaminated cases: outcomes of 33,832 cases. Ann Surg 255: 176-180.

29. Kanters AE, Krpata DM, Blatnik JA, Novitsky YM, Rosen MJ (2012) Modified hernia grading scale to stratify surgical site occurrence after open ventra hernia repairs. J Am Coll Surg 215: 787-793.

30. Sanchez VM, Abi-Haidar YE, Itani KM (2011) Mesh infection in ventral incisional hernia repair: Incidence, contributing factors and treatment. Surg Infect (Larchmt) 12: 205-210.

31. El-Gazzaz G, Erem HH, Aytac E, Salcedo L, Stocchi L, et al. (2013) Risk of infection and hernia recurrence for patients undergoing ventral hernia repair with non-absorbable or biological mesh during open bowel procedures. Tech Coloproctol 17: 315-320.

32. Hawn MT, Gray SH, Snyder CW, Graham LA, Finan KR, et al. (2011) Predictors of mesh explantation after incisional hernia repair. Am J Surg 202: 28-33.

33. Liang MK, Goodenough CJ, Martindale RG, Roth JS, Kao LS (2015) Externa validation of the ventral hernia risk score for prediction of surgical site infections. Surg Infect (Larchmt) 16: 36-40.

34. Dunne JR, Malone DL, Tracy JK, Napolitano LM (2003) Abdominal wall hernias: Risk factors for infection and resource utilization. J Surg Res 111: 78-84.

35. Blatnik JA, Krpata DM, Novitsky YW, Rosen MJ (2012) Does a history of wound infection predict postoperative surgical site infection after ventral hernia repair? Am J Surg 203: 370-374.

36. Murray BW, Cipher DJ, Pham T, Anthony T (2011) The impact of surgical site infection on the development of incisional hernia and small bowel obstruction in colorectal surgery. Am J Surg 202: 558-560.

37. Sippey M, Mozer AB, Grzybowski M, Manwaring ML, Kasten KR, et al. (2015) Obstructing ventral hernias are not independently associated with surgical site infections. J Surg Res 199: 326-330.

38. Pinell-White XA, Gruszynski M, Losken A (2014) Ventral hernia repair after bowel surgery: Does gastrointestinal contamination matter in the era of biologic mesh? Ann Plast Surg 72: S150-152.

39. Carbonell AM, Criss CN, Cobb WS, Novitsky YW, Rosen MJ (2013) Outcomes of synthetic mesh in contaminated ventral hernia repairs. J Am Coll Surg 217: 991-998.

40. Krpata DM, Blatnik JA, Novitsky YW, Rosen MJ (2013) Evaluation of high-risk comorbid patients undergoing open ventral hernia repair with synthetic mesh. Surgery 153: 120-125. 
41. Fischer JP, Wes AM, Wink JD, Nelson JA, Rohrbach JI, et al. (2014) Analysis of perioperative factors associated with increased cost following abdominal wall reconstruction (AWR). Hernia 18: 617-624

42. Hawn MT, Snyder CW, Graham LA, Gray SH, Finan KR, et al. (2010) Long-term follow-up of technical outcomes for incisional hernia repair. J Am Coll Surg 210: 648-655.

43. Ousley J, Baucom RB, Stewart MK, Phillips SE, Holzman MD, et al. (2015) Previous methicillin-resistant Staphylococcus aureus infection independent of body site increases odds of surgical site infection after ventral hernia repair. J Am Coll Surg 221: 470-477.

44. Hicks CW, Blatnik JA, Krpata DM, Novitsky YW, Rosen MJ (2014) History of methicillin-resistant Staphylococcus aureus (MRSA) surgical site infection may not be a contraindication to ventral hernia repair with synthetic mesh: $A$ preliminary report. Hernia 18: 65-70.

45. An YH, Friedman RJ (1998) Concise review of mechanisms of bacterial adhesion to biomaterial surfaces. J Biomed Mater Res 43: 338-348.

46. Katsikogianni M, Missirlis YF (2004) Concise review of mechanisms of bacterial adhesion to biomaterials and of techniques used in estimating bacteria-material interactions. Eur Cell Mater 8: 37-57.

47. Eroshenko D, Morozov I, Korobov V (2015) The role of plasma, albumin and fibronectin in Staphylococcus epidermidis adhesion to polystyrene surface. Curr Microbiol 70: 846-853.

48. Dietz UA, Spor L, Germer CT (2011) Management of mesh-related infections. Chirurg 82: 208-217.

49. Sanders DL, Kingsnorth AN, Lambie J, Bond P, Moate R, et al. (2013) An experimental study exploring the relationship between the size of bacterial inoculum and bacterial adherence to prosthetic mesh. Surg Endosc 27: 978-985.

50. Taylor SG, O'Dwyer PJ (1999) Chronic groin sepsis following tension-free inguinal hernioplasty. $\mathrm{Br} \mathrm{J}$ Surg 86: 562-565.

51. Nolla-Salas J, Torres-Rodriguez JM, Grau S et al. (2000) Successful treatment with liposomal amphotericin B of an intra-abdominal abscess due to Candida norvegensis associated with a Gore-Tex mesh infection. Scand J Infect Dis 32: 560-562.

52. Matthews MR, Caruso DM, Tsujimura RB, Smilack JD, Pockaj BA, et al. (1999) Ventral hernia synthetic mesh repair infected by Mycobacterium fortuitum. Am Surg 65: 1035-1037.

53. Bilsel Y, Abci I (2012) The search for ideal hernia repair; mesh materials and types. Int J Surg 10: 317-321.

54. Cevasco M, Itani KM (2012) Ventral hernia repair with synthetic, composite and biologic mesh: Characteristics, indications and infection profile. Surg Infect (Larchmt) 13:209-215.

55. Demirer S, Geçim IE, Aydinuraz K, Ataoğlu H, Yerdel MA, et al. (2001) Affinity of Staphylococcus epidermidis to various prosthetic graft materials. J Surg Res 99: 70-74.

56. Sanders D, Lambie J, Bond P, Moate R, Steer JA (2013) An in vitro study assessing the effect of mesh morphology and suture fixation on bacterial adherence. Hernia 17: 779-789.

57. Brown RH, Subramanian A, Hwang CS, Chang S, Awad SS (2013) Comparison of infectious complications with synthetic mesh in ventral hernia repair. Am J Surg 205: 182-187.

58. Harrell AG, Novitsky YW, Kercher KW, Foster M, Burns JM, et al. (2006) In vitro infectability of prosthetic mesh by methicillin-resistant Staphylococcus aureus. Hernia 10: 120-124.

59. Blatnik JA, Krpata DM, Jacobs MR, Gao Y, Novitsky YW, et al. (2012) In vivo analysis of the morphologic characteristics of synthetic mesh to resist MRSA adherence. J Gastrointest Surg 16: 2139-2144.

60. Aydinuraz K, Ağalar C, Ağalar F, Ceken S, Duruyürek N, et al. (2009) In vitro $S$. epidermidis and $S$. aureus adherence to composite and lightweight polypropylene grafts. J Surg Res 157: e79-86.

61. Díaz-Godoy A, García-Ureña MA, López-Monclús J, Vega Ruíz V, Melero Montes D, et al. (2011) Searching for the best polypropylene mesh to be used in bowel contamination. Hernia 15: 173-179.

62. Novik B (2007) Fibrin glue mesh fixation in hernia repair. Ann Surg 246: 906-908.

63. Stoikes N, Sharpe J, Tasneem H, Roan E, Paulus E, et al. (2015) Biomechanical evaluation of fixation properties of fibrin glue for ventral incisional hernia repair. Hernia 19: 161-166.
64. Shahan CP, Stoikes NF, Webb DL, Voeller GR (2015) Sutureless on lay hernia repair: A review of 97 patients. Surg Endosc Nov 5 .

65. Yerdel MA, Akin EB, Dolalan S, Turkcapar AG, Pehlivan M, et al. (2001) Effect of single-dose prophylactic ampicillin and sulbactam on wound infection after tension-free inguinal hernia repair with polypropylene mesh: The randomized, double-blind, prospective trial. Ann Surg 233: 26-33.

66. Mazaki T, Mado K, Masuda H, Shiono M (2013) Antibiotic prophylaxis for the prevention of surgical site infection after tension-free hernia repair: A Bayesian and frequentist meta-analysis. J Am Coll Surg 217: 788-801.

67. Mazaki T, Mado K, Masuda H, Shiono M, Tochikura N, et al. (2014) A randomized trial of antibiotic prophylaxis for the prevention of surgical site infection after open mesh-plug hernia repair. Am J Surg 207: 476-484.

68. Wong A, Lee S, Nathan NS, Wang F, Hansen SL, et al. (2016) Postoperative prophylactic antibiotic use following ventral hernia repair with placement of surgical drains reduces the postoperative surgical-site infection rate. Plast Reconstr Surg 137: 285-294.

69. Mehrabi Bahar M, Jabbari Nooghabi A, Jabbari Nooghabi M, Jangjoo A (2015) The role of prophylactic cefazolin in the prevention of infection after various types of abdominal wall hernia repair with mesh. Asian J Surg 38: 139-144.

70. Stoodley P, Conti SF, DeMeo PJ, Nistico L, Melton-Kreft R, et al. (2011) Characterization of a mixed MRSA/MRSE biofilm in an explanted total ankle arthroplasty. FEMS Immunol Med Microbiol 62: 66-74.

71. Frei E, Hodgkiss-Harlow K, Rossi PJ, Edmiston CE Jr, Bandyk DF (2011) Microbial pathogenesis of bacterial biofilms: A causative factor of vascular surgical site infection. Vasc Endovascular Surg 45: 688-696.

72. Agalar C, Ozdogan M, Agalar F, Saygun O, Aydinuraz K, et al. (2006) A rat model of polypropylene graft infection caused by Staphylococcus epidermidis. ANZ J Surg 76: 387-391.

73. Kathju S, Nistico L, Tower I, Lasko LA, Stoodley P (2014) Bacterial biofilms on implanted suture material are a cause of surgical site infection. Surg Infect (Larchmt) 15: 592-600

74. Kathju S, Nistico L, Melton-Kreft R, Lasko LA, Stoodley P (2015) Direct demonstration of bacterial biofilms on prosthetic mesh after ventra herniorrhaphy. Surg Infect (Larchmt) 16: 45-53.

75. Almshawit H, Macreadie I, Grando D (2014) A simple and inexpensive device for biofilm analysis. J Microbiol Methods 98: 59-63.

76. Troy MG, Dong QS, Dobrin PB, Hecht D (1996) Do topical antibiotics provide improved prophylaxis against bacterial growth in the presence of polypropylene mesh? Am J Surg 171: 391-393.

77. Sadava EE, Krpata DM, Gao Y, Novitsky YW, Rosen MJ (2013) Does presoaking synthetic mesh in antibiotic solution reduces mesh infections? An experimental study. J Gastrointest Surg 17: 562-568.

78. Wiegering A, Sinha B, Spor L, Klinge U, Steger U, et al. (2014) Gentamicin for prevention of intraoperative mesh contamination: Demonstration of high bactericide effect (in vitro) and low systemic bioavailability (in vivo). Hernia 18 691-700.

79. Pérez-Köhler B, García-Moreno F, Bayon Y, Pascual G, Bellón JM (2015) Inhibition of Staphylococcus aureus adhesion to the surface of a reticular heavyweight polypropylene mesh soaked in a combination of chlorhexidine and allicin: An in vitro study. PLoS One 11: e0126711.

80. Pérez-Köhler B, García-Moreno F, Brune T, Pascual G, Bellón JM (2015) Preclinical bioassay of a polypropylene mesh for hernia repair pretreated with antibacterial solutions of chlorhexidine and allicin: An in vivo study. PLoS One 10: e0142768

81. Yabanoğlu H, Arer IM, Çalıskan K (2015) The effect of the use of synthetic mesh soaked in antibiotic solution on the rate of graft infection in ventral hernias: $A$ prospective randomized study. Int Surg 100: 1040-1047.

82. Campoccia D, Montanaro L, Arciola CR (2013) A review of the biomaterials technologies for infection-resistant surfaces. Biomaterials 34: 8533-8554.

83. Yu Q, Wu Z, Chen H (2015) Dual-function antibacterial surfaces for biomedical applications. Acta Biomater 16: 1-13.

84. Harth KC, Rosen MJ, Thatiparti TR, Jacobs MR, Halaweish I, et al. (2010) Antibiotic-releasing mesh coating to reduce prosthetic sepsis: An in vivo study. J Surg Res 163: 337-343.

85. Siedenbiedel F, Tiller JC (2012) Antimicrobial polymers in solution and on surfaces: Overview and functional principles. Polymers 4: 46-71. 
86. Pérez-Köhler B, Fernández-Gutiérrez M, Pascual G, García-Moreno F, San Román J, et al. (2016) In vitro assessment of an antibacterial quaternary ammonium-based polymer loaded with chlorhexidine for the coating of polypropylene prosthetic meshes. Hernia 20: 869-878.

87. Thallinger B, Prasetyo EN, Nyanhongo GS, Guebitz GM (2013) Antimicrobial enzymes: An emerging strategy to fight microbes and microbial biofilms. Biotechnol J 8: 97-109.

88. Kumar JK (2008) Lysostaphin: An anti-staphylococcal agent. Appl Microbiol Biotechnol 80: 555-561.

89. Yurko Y, McDeavitt K, Kumar RS, Martin T, Prabhu A, et al. (2012) Antibacterial mesh: A novel technique involving naturally occurring cellular proteins. Surg Innov 19: 20-26.

90. Satishkumar R, Sankar S, Yurko Y, Lincourt A, Shipp J, et al. (2011) Evaluation of the antimicrobial activity of lysostaphin-coated hernia repair meshes. Antimicrob Agents Chemother 55: 4379-4385.

91. Belyansky I, Tsirline VB, Montero PN, Satishkumar R, Martin TR, et al. (2011) Lysostaphin-coated mesh prevents staphylococcal infection and significantly improves survival in a contaminated surgical field. Am Surg 77: 1025-1031.

92. Belyansky I, Tsirline VB, Martin TR, Klima DA, Heath J, et al. (2011) The addition of lysostaphin dramatically improves survival, protects porcine biomesh from infection and improves graft tensile shear strength. J Surg Res 171: 409-415.

93. Laurent T, Kacem I, Blanchemain N, Cazaux F, Neut C, et al. (2011) Cyclodextrin and maltodextrin finishing of a polypropylene abdominal wall implant for the prolonged delivery of ciprofloxacin. Acta Biomater 7: 3141-3149.

94. Kilic D, Agalar C, Ozturk E, Denkbas EB, Cime A, et al. (2007) Antimicrobial activity of cefazolin-impregnated mesh grafts. ANZ J Surg 77: 256-260.

95. Suárez-Grau JM, Morales-Conde S, González Galán V, Martín Cartes JA Docobo Durantez F, et al. (2015) Antibiotic embedded absorbable prosthesis for prevention of surgical mesh infection: Experimental study in rats. Hernia 19: 187-194.

96. Letouzey V, Lavigne JP, Garric X, Coudane J, de Tayrac R, et al. (2012) Is degradable antibiotic coating for synthetic meshes provide protection against experimental animal infection after fascia repair? J Biomed Mater Res B Appl Biomater 100: 471-479.

97. Labay C, Canal JM, Modic M, Cvelbar U, Quiles M, et al. (2015) Antibioticloaded polypropylene surgical meshes with suitable biological behaviour by plasma functionalization and polymerization. Biomaterials 71: 132-144.

98. Guillaume O, Lavigne JP, Lefranc O, Nottelet B, Coudane J, Garric X (2011) New antibiotic-eluting mesh used for soft tissue reinforcement. Acta Biomater 7: 3390-3397.

99. Guillaume O, Garric X, Lavigne JP, Van Den Berghe H, Coudane J (2012) Multilayer, degradable coating as a carrier for the sustained release of antibiotics: Preparation and antimicrobial efficacy in vitro. J Control Release 162: 492-501.

100. Fernandez-Gutierrez M, Olivares E, Pascual G, Bellon JM, San Román $J$ (2013) Low-density polypropylene meshes coated with resorbable and biocompatible hydrophilic polymers as controlled release agents of antibiotics. Acta Biomater 9: 6006-6018.

101.Junge K, Rosch R, Klinge U, Krones C, Klosterhalfen B, et al. (2005) Gentamicin supplementation of polyvinylidenfluoride mesh materials for infection prophylaxis. Biomaterials 26: 787-793.

102. Klink CD, Binnebösel M, Lambertz A, Alizai HP, Roeth A, et al. (2012) In vitro and in vivo characteristics of gentamicin-supplemented polyvinylidenfluoride mesh materials. J Biomed Mater Res 100: 1195-1202.

103. Pelgrift RY, Friedman AJ (2013) Nanotechnology as a therapeutic tool to combat microbial resistance. Adv Drug Deliv Rev 65: 1803-1815.

104. Engelsman AF, Krom BP, Busscher HJ, van Dam GM, Ploeg RJ, et al. (2009) Antimicrobial effects of an NO-releasing poly[ethylene vinylacetate] coating on soft-tissue implants in vitro and in a murine model. Acta Biomater 5: 1905-1910.

105. Wo Y, Brisbois EJ, Bartlett RH, Meyerhoff ME (2016) Recent advances in thromboresistant and antimicrobial polymers for biomedical applications: Just say yes to nitric oxide (NO). Biomater Sci 19: 1161-1183.

106. Petersen RC (2016) Triclosan antimicrobial polymers. AIMS Mol Sci 3: 88-103.

107. Cakmak A, Cirpanli Y, Bilensoy E, Yorganci K, Caliş S, et al. (2009) Antibacterial activity of triclosan chitosan coated graft on hernia graft infection model. Int $\mathrm{J}$ Pharm 381: 214-219.
108. Liu Z, Wang C, Liu Y, Peng D (2017) Cefepime loaded O-carboxymethy chitosan microspheres with sustained bactericidal activity and enhanced biocompatibility. J Biomater Sci Polym Ed 28: 79-92.

109. Chakraborty SP, Sahu SK, Pramanik P, Roy S (2012) In vitro antimicrobial activity of nanoconjugated vancomycin against drug resistant Staphylococcus aureus. Int J Pharm 436: 659-676.

110. Raghunath A, Perumal E (2017) Metal oxide nanoparticles as antimicrobial agents: A promise for the future. Int J Antimicrob Agents.

111. Lai HZ, Chen WY, Wu CY, Chen YC (2015) Potent antibacterial nanoparticles for pathogenic bacteria. ACS Appl Mater Interfaces 7: 2046-2054.

112. Chaloupka K, Malam Y, Seifalian AM (2010) Nanosilver as a new generation of nanoproduct in biomedical applications. Trends Biotechnol 28: 580-588.

113. Rai MK, Deshmukh SD, Ingle AP, Gade AK (2012) Silver nanoparticles: the powerful nanoweapon against multidrug-resistant bacteria. J Appl Microbiol 112: 841-852.

114. Morones JR, Elechiguerra JL, Camacho A, Holt K, Kouri JB, et al. (2005) The bactericidal effect of silver nanoparticles. Nanotechnology 16: 2346-2353.

115. Cohen MS, Stern JM, Vanni AJ, Kelley RS, Baumgart E, et al. (2007) In vitro analysis of a nanocrystalline silver-coated surgical mesh. Surg Infect 8: 397-403.

116. Kumar V, Jolivalt C, Pulpytel J, Jafari R, Arefi-Khonsari F (2013) Development of silver nanoparticle loaded antibacterial polymer mesh using plasma polymerization process. J Biomed Mater Res A 101: 1121-1132.

117. Saygun O, Agalar C, Aydinuraz K, Agalar F, Daphan C, et al. (2006) Gold and gold-palladium coated polypropylene grafts in a $S$. epidermidis wound infection model. J Surg Res 131: 73-79.

118. Visai L, De Nardo L, Punta C, Melone L, Cigada A, et al. (2011) Titanium oxide antibacterial surfaces in biomedical devices. Int J Artif Organs 34: 929-946.

119. Aboelzahab A, Azad AM, Dolan S, Goel V (2012) Mitigation of Staphylococcus aureus-mediated surgical site infections with ir photoactivated $\mathrm{TiO}_{2}$ coatings on Ti implants. Adv Health Mater 1: 285-291.

120. Kashef N, Akbarizare M, Razzaghi MR (2017) In vitro activity of linezolid in combination with photodynamic inactivation against Staphylococcus aureus biofilms. Avicenna J Med Biotechnol 9: 44-48.

121. Akram FE, El-Tayeb T, Abou-Aisha K, El-Azizi M (2016) A combination of silver nanoparticles and visible blue light enhances the antibacterial efficacy of ineffective antibiotics against methicillin-resistant Staphylococcus aureus (MRSA). Ann Clin Microbiol Antimicrob 15: 48.

122. Cahan R, Schwartz R, Langzam Y, Nitzan Y (2011) Light-activated antibacterial surfaces comprise photosensitizers. Photochem Photobiol 87: 1379-1386.

123. Guo Y, Rogelj S, Zhang P (2010) Rose Bengal-decorated silica nanoparticles as photosensitizers for inactivation of gram-positive bacteria. Nanotechnology 21: 065102.

124. Tsai T, Chien HF, Wang TH, Huang CT, Ker YB, Chen CT (2011) Chitosan augments photodynamic inactivation of gram-positive and gram-negative bacteria. Antimicrob Agents Chemother 55: 1883-1890.

125. Wu X, Huang YY, Kushida Y, Bhayana B, Hamblin MR (2016) Broadspectrum antimicrobial photocatalysis mediated by titanium dioxide and UVA is potentiated by addition of bromide ion via formation of hypobromite. Free Radic Biol Med 95: 74-81.

126. Sharma SK, Chiang LY, Hamblin MR (2011) Photodynamic therapy with fullerenes in vivo: Reality or a dream? Nanomedicine 6: 1813-1825.

127. Maas M (2016) Carbon nanomaterials as antibacterial colloids. Materials 9: 617.

128. Rajavel K, Gomathi R, Manian S, Rajendra Kumar RT (2014) In vitro bacterial cytotoxicity of CNTs: Reactive oxygen species mediate cell damage edges over direct physical puncturing. Langmuir 30: 592-601.

129. Rai M, Ingle AP, Gaikwad S, Gupta I, Gade A, Silvério da Silva S (2016) Nanotechnology based anti-infective to fight microbial intrusions. J App Microbiol 120: 527-542.

130. Hamblin MR (2016) Antimicrobial photodynamic inactivation: A bright new technique to kill resistant microbes. Curr Opin Microbiol 33: 67-73.

131. Mizuno K, Zhiyentayev T, Huang L, Khalil S, Nasim F, et al. (2011) Antimicrobia photodynamic therapy with functionalized fullerenes: Quantitative structureactivity relationships. J Nanomed Nanotechnol 2: 1-9. 